\title{
Tadris Maharah Al-Qiroah li An-Nahtiqiin bi Ghairiha Al-Usus An-Nazhariah wa Al-Istiratijiyat Ath-Thatbiqiyah
}

\author{
تدريس مهارة القراءة للناطقين بغير العربية \\ الأسس النظرية والاستر اتيجيات التطبيقية
}

Sanaa Allal Lahlali ${ }^{1}$,E-mail: sanaa.lahlali15@gmail.com, Menara El Arabiya for Arabic Studies, Morocco

\section{(c) (1) ()}

This is an open access article under the CC-BY-SA license

(C)2021 by the authors. Submitted for possible open access publication under the terms and conditions of the Creative Commons Attribution-ShareAlike 4.0 International License-(CC-BY-SA) (https://creativecommons.org/licenses/by-sa/4.0/)

do) DOI: http://dx.doi.org/10.30983/buruf.v1i1.5103

\begin{abstract}
This research paper highlights the reading skill in teaching Arabic to other speakers as a receptive skill (listening-reading) that contributes to enriching the learner's language ammunition. The research is made up of two parts: a theoretical part: it focuses on the importance of reading skill, while presenting its types and the purpose of its teaching. And a practical one which deals with the most important strategies used while presenting a reading lesson. This research paper is based on theoretical ideas derived from the heart of applied linguistics, as well as from applied study based on, on the one hand, an educational experience that I have gained while teaching non-Arabic speakers from different countries and nationalities, as well as benefiting from some training courses developed by academic specialists in Arabic language education for nonnative speakers of Arabic. On the other hand, it benefits from specialized and varied linguistic sources and references.
\end{abstract}

Keywords: Reading, intensive reading, extended, effective, silent, based, strategies

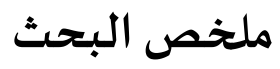

تروم هذه الورقة البحثية تسليط الضيوء على مهارة القراءة في مجال تعليم اللغة العربية للناطقين بغيرها؛ باعتبارها من المهارات الاستقبالية (الاستماع- القراءة) التي تسهم في إغناء الذخيرة اللغوية لدى المتعلم. ويتكون البحث من شقين: شق نظري: تطرق لماهية القراءة وأهميتها، مع عرض أنواعها والهدف من تدريسها.وشق تطبيقي تم فيه عرض أهم الاستراتيجيات المتبعة في تقديم القراءة. تستند هذه الورقة البحثية إلى أفكار نظرية مستمدة من صهميم اللسانيات التطبيقياة، و وإلى دراسة تطبيقية ميدانياة ترتكز - من جهاة - على تجربة تربوية خضناها في تدريس الناطقين بغير العربية من دول وجنسيات 
مختلفة، فضلا عن استفادتي - حضوريا - من بعض الدورات التدريبية التي أطرها خبراء دوليون. وترتكز من جهة أخرى على مصادر ومراجع لسانية متخصصية ومتنوعة. الكلمات المفتاحية: قراءة- مكثفة، موسعاة، فعالة، صامتة، جهبية، استراتيجية

مقدمة

تعد مهارة القراءة مهارة أساسية من مهارات تعلم أي لغذة، وهي تأتي في المرتبة الثالثة

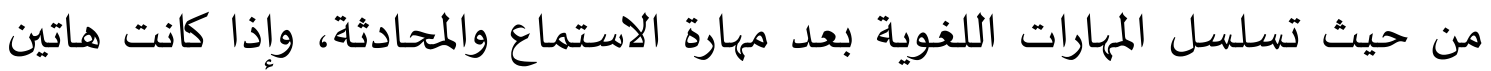
المهارتين مكتسبتان يكتسبهما الطفل بالفطرة. فإن مهارة القراءة مهارة متعلمة يحتاج الطفل فيها إلى معلم وإلى وقت حتى يتعلمها. وتكمن أهمية هذه المهارة في كونها المدخل

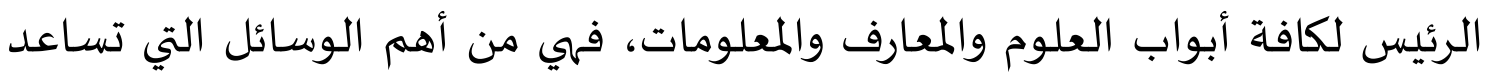

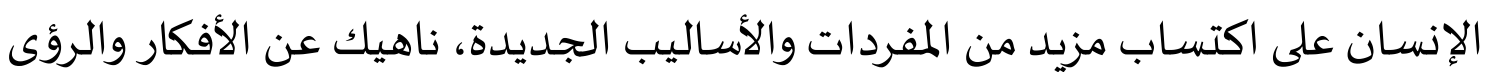

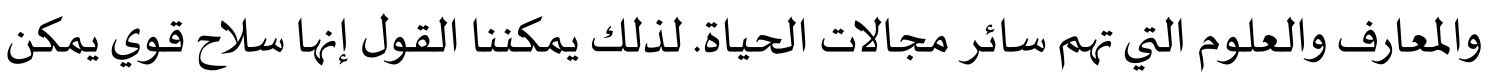

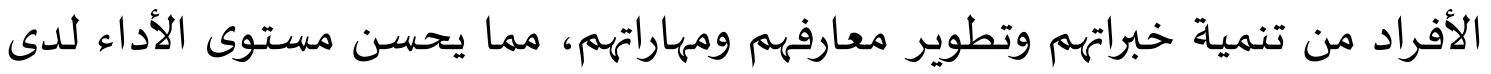

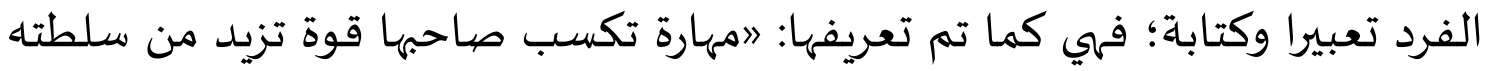

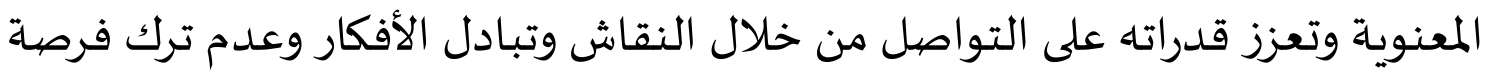

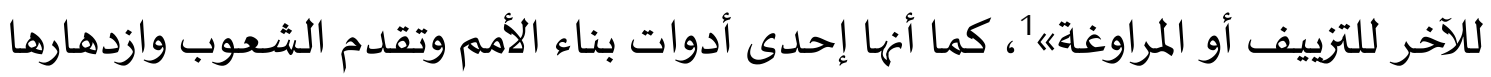

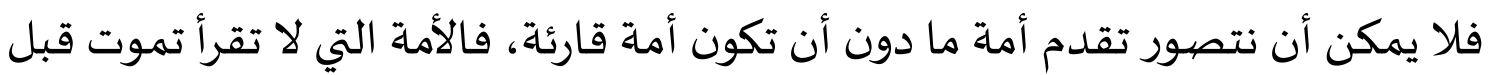
أوانها كما قيل قديما.

\section{1- تعريف القراءة}

يعرف بوشـوك القراءة بكونها 》عمليات الإدراك السيكو بصرية للرموز الخطية،

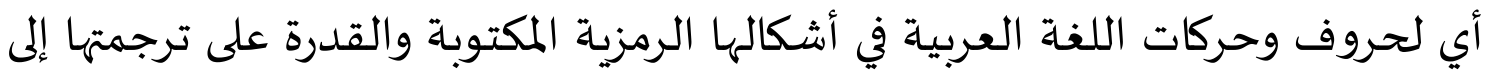

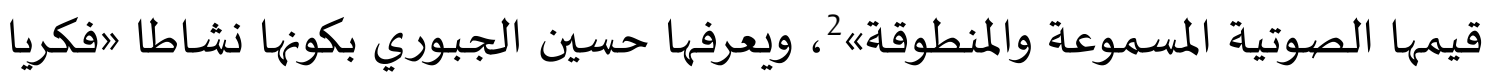

1 - إسماعيلي علوي، امحمد، 2012، التواصل الإنساني: دراسة لسانية. ط.1، كنوز المعرفة، عمان، الأردن، ص:

2 - بوشوك، المصطفى. تعليم وتعلم اللغة العربية وثقافتها . دراسة نظرية وميد/نية في: تشخيص الصعوبات. اقتراح مقاربات ومناهج ديداكتيكية- بناء تصنيف ثلاثي الأبعاد في الأهداف اللسانية. 
يقوم على انتقال الذهن من الحروف والأشكال التي تقع تحت الأنظار إلى الأصوات والألفاظ التي تدل عليها وترمز إليها《3.

انطلاقا من ملاحظتنا للتعريفين اللذين قدمهما كل من بوشوك والجبوري

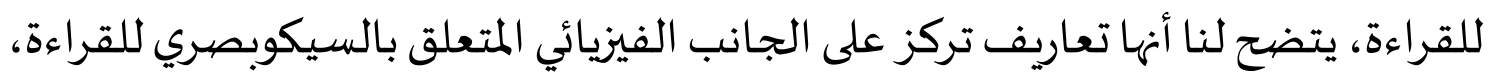

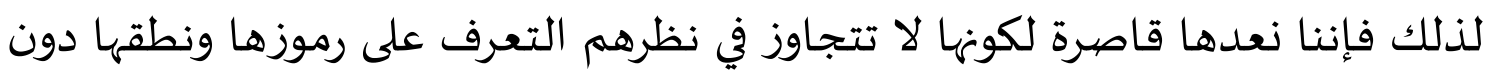

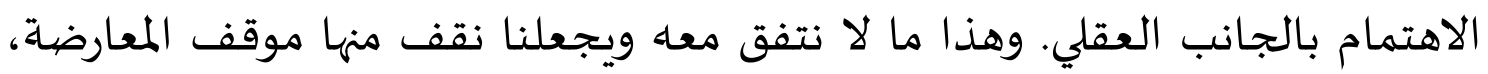

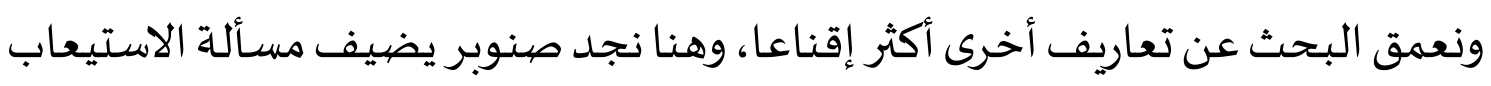
إلى واجهاة تعريفه للقراءة قائلا: هي "اسلساة عمليات هدفها الاستيعاب يقوم بها القارئ

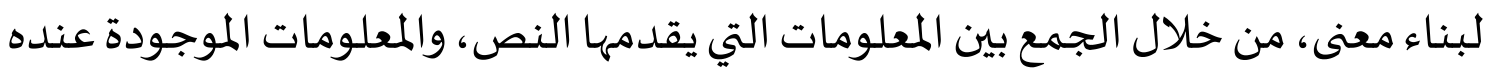

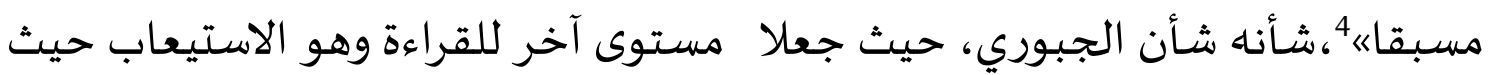

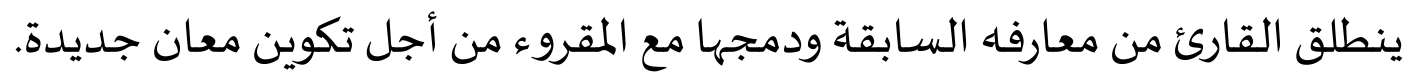
وعلى الرغم من هذه الإضيافة إلا أن هذا التعريف ما زلنا نراه قاصرا، وذلك لعدم ربطه

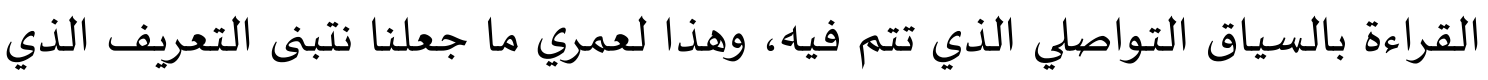

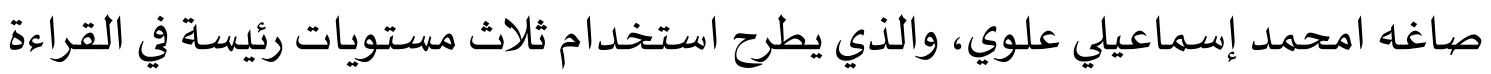

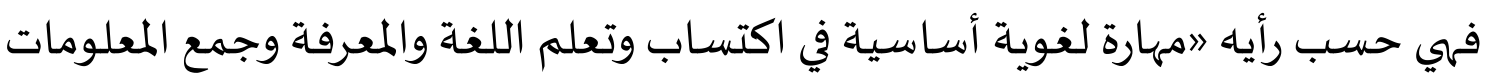
والتواصل مع المحيط. وهي ذات مستويات ثلاثة: مستوى القراءة الخطية البصرية،

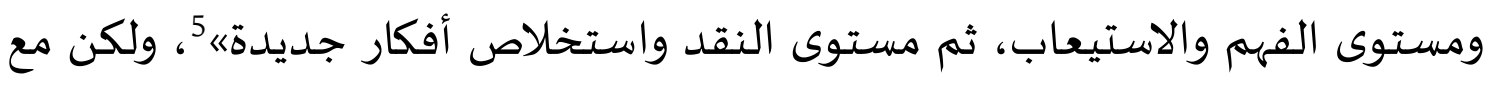
إضافة مستوى رابع يهم مستوى توظيف المقروء في مواقف تواصلية حقيقياة. وعليه، وانطلاقا مما سبق، يمكننا أن نقول إن القراءة آلية لغوية يكتسب من خلالها

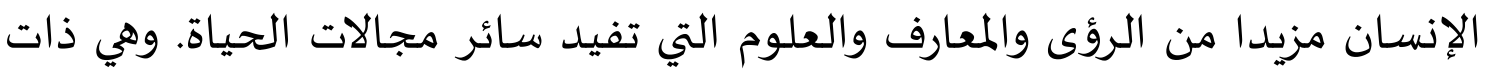

3 - الجبوري، فلاح صالح حسين، (2015)، طريق تلديس اللغة العبية في ضوء معايير الجودة الشاملة. ط.1، دار

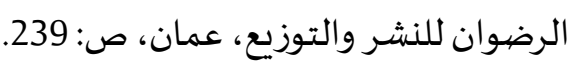
4 - صنوبر، أحمد عبدالجباروآخرون، (تدريس مهارة القراءة النظرية والتطبيق) الدليل التدريبي في تلدريس

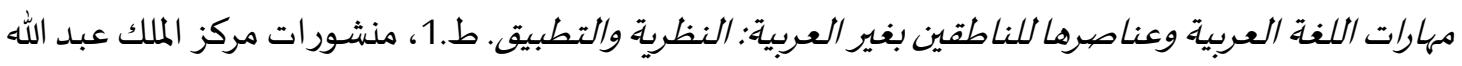

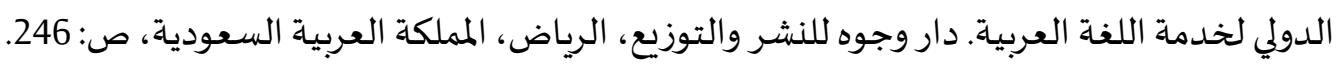
5 - إسماعيلي علوي، محمد، تقنيات تنمية وتطوير مهارة القراءة (مرجع سابق)، ص: 44. 
مستويات أربع: مستوى فك الرموز المكتوبة،6، ومستوى ترجمة هذه الرموز إلى معان، ثم

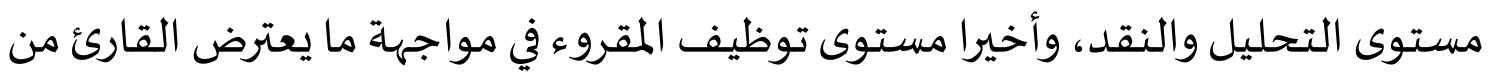

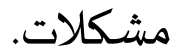

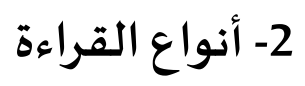

تنقسم القراءة إلى أنواع كثيرة'، فمن حيث الفعالية تنقسم إلى:

- قراءة فعالة:وهي القراءة التي تمكن صاحبها من امتلاك المعرفة، واستيعاب المعلومات

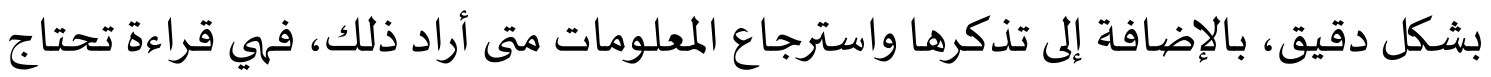
إلى تركيز عال، وإلى وقت أقل مع تحصيل أكبر..

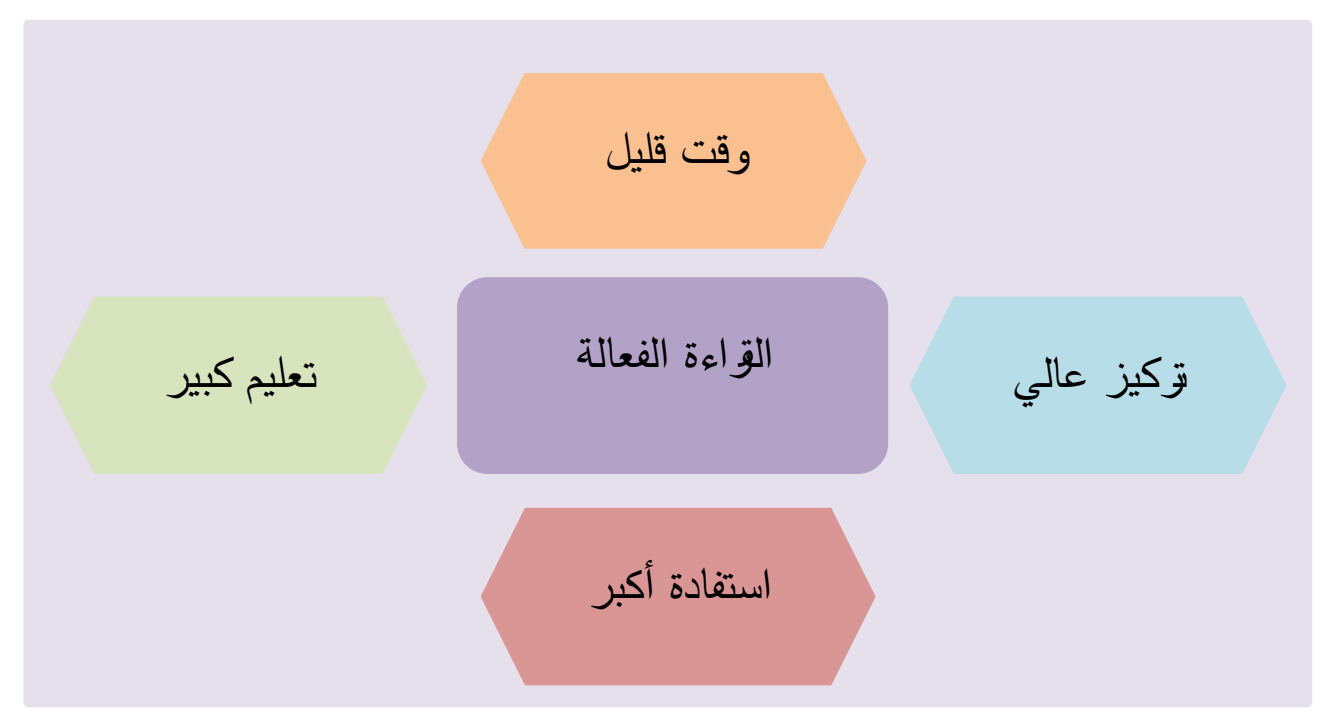

\section{الرسم التوضيحي رقم (01): مميزات القراءة الفعالة}

- قراءة سلبية: وهي القراءة التي لا يحقق من خلالها القارئ أي استفادة، ولا يتذكر شيئا

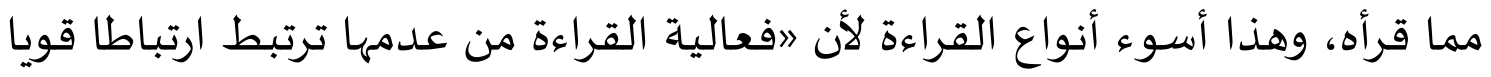

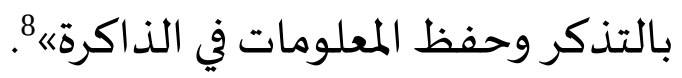

${ }^{6}$-Brain, Tomlinson (2007). Language Acquisition and devlopment studies of Learners of first and others languages, Athenaeum press Ltd, tyne and wear, Britain, p: 16.

$$
7 \text { - } 7 \text { - إسماعيلي علوي، محمد. التواصل الإنساني (مرجع سابق)، ص: } 51 .
$$




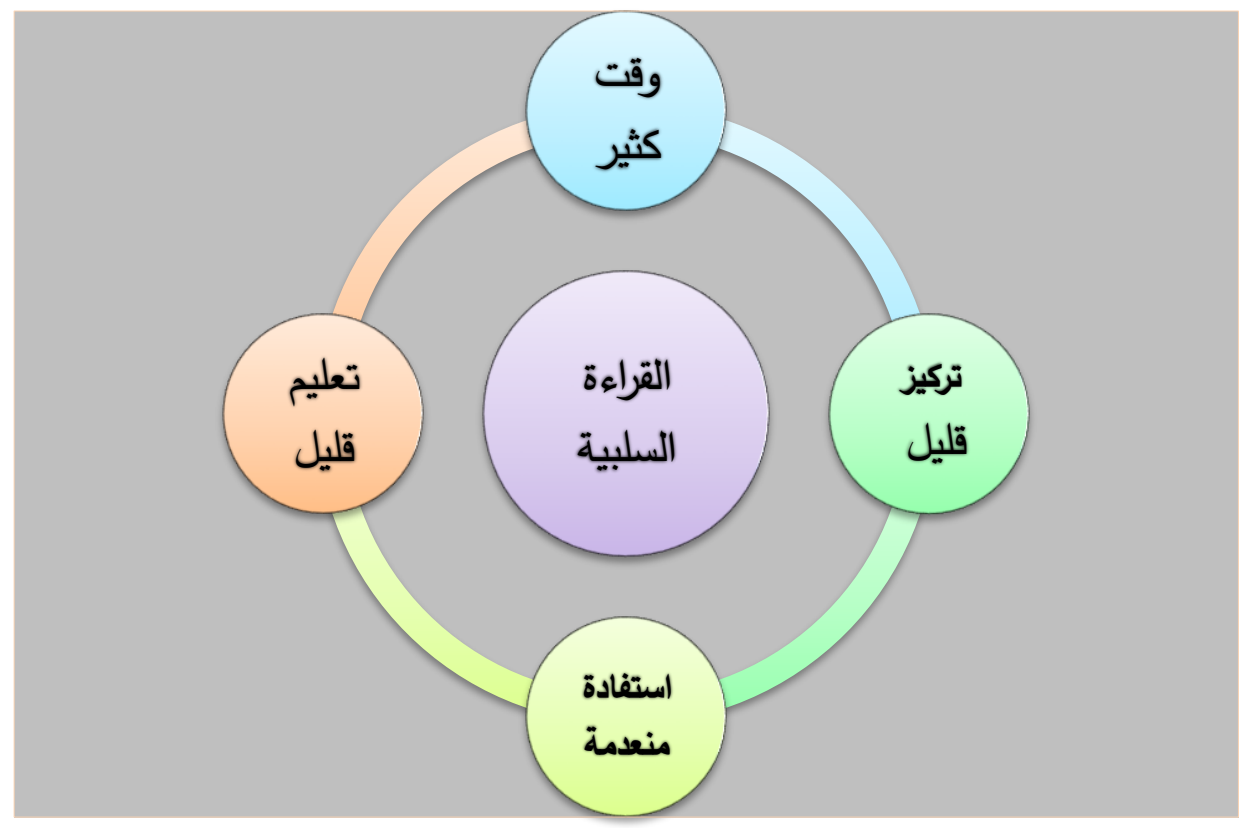

\section{الرسم التوضيحي(02): يبين القراءة السلبية}

وتنقسم القراءة بالنسبة لعدد الكلمات المقروءة في الدقيقة إلى:

- قراءة ضعيفة: وهي القراءة التي يكون عدد كلماتها أقل من 100 كلمة في الدقيقة. - قراءة متوسطة: وهي القراءة التي يصل عدد كلماتها إلى 250 كلمة في الدقيقة. - قراءة سريعة: وهي القراءة التي تصل إلى 1000 كلمة في الدقيقة. تنقسم القراءة حسب الصوت إلى:

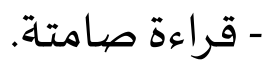

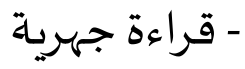
وتنقسم بحسب الصف إلى: - قراءة مكثفة: وهي القراءة التي تكون داخل الفصل الدراسي. 


\section{- قراءة موسعة: وهي القراءة التي تكون خارج الصفوف الدراسية.}

وسنتناول من هذه التقسيمات ما له ارتباط وثيق بتعليم مهارة القراءة للناطقين بغير

$$
\text { العربية وما يمكن أن يساعد في تحقيق هذه أهد افها. }
$$

\section{2-1 2-1 القراءة الجهرية والصامتة}

2-1-1- القراءة الجهرية: المقصود بها ترجمة الرموز المكتوبة إلى حروف منطوقة بصوت مسموع، وهي تعتمد أولا على الرؤية البصرية للرموز ثم إدراكها وفهم معانيها، وأخيرا

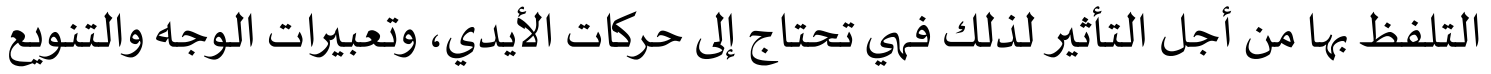

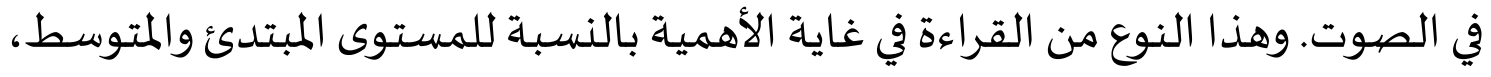
وذلك 》لأهها تتيح فرصة كبيرة للتدرب على النطق الصحيح ورمزه المكتوب ولذلك يقال إنه

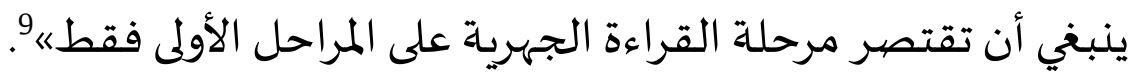

إن القراءة الجهرية هي أول مرحلة من مراحل تعلم القراءة، فهي خطوة أساسية قبل

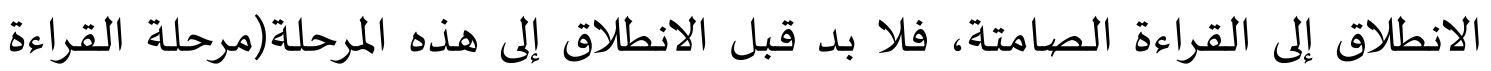

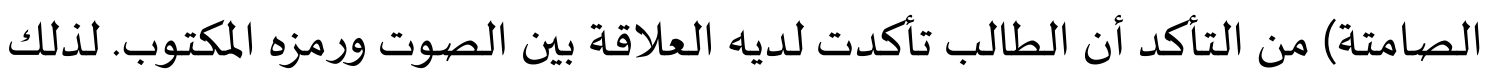
لا يجب أن تغفل القراءة الجهرية في صفوف تعليم اللغة العربية للناطقين بغيرها خاصية

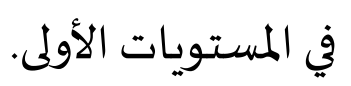

2-1-2 القراءة الصامتة: وهي القراءة التي يتم فيها التعرف على مدلولات الرموز في ذهن القارئ من دون صوت أو تحريك للشفاه. وتعتمد على مستويين فقط مستوى فك الرموز

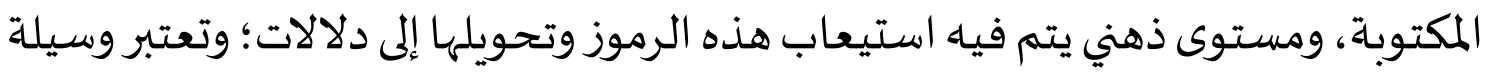
مهمة من وسائل الثروة اللفظية عند الطالب وربطه باللغة واستعمالها في التفكير والاتصيال.

9 - الناقة، محمود كامل.، (2017)، المبرجع المعاصر في تعليم العربية للناطقين بغيرها، ط.1، دار الفكر العربي، القاهرة، مصر، ص:136. 


$$
\text { وهي تسعى إلى تحقيق مجموعة من الأهداف10 منها: }
$$

- التقاط خلاصة المقروء أي استيعاب الرسالة، وليس الرمز، أي التركيز على الدقة في

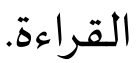

- معرفة الجديد في ميادين المعرفة المختلفة. - القراءة السريعة الخاطفة في الكتب التي لا تحتاج إلى تأمل. - القراءة من أجل الاستمتاع والترفياء وقضاء الوقت.

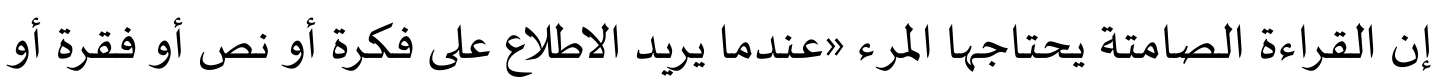

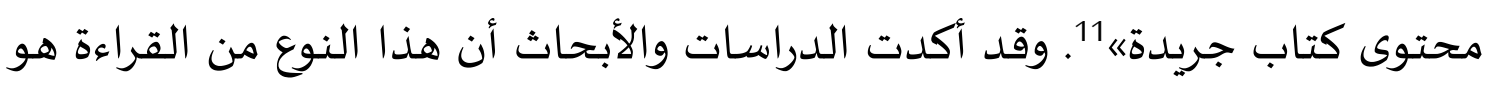

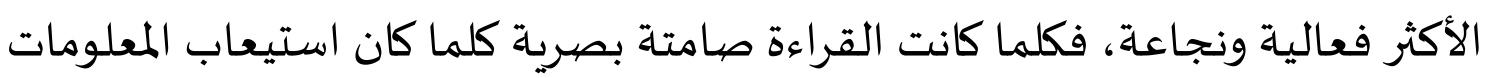

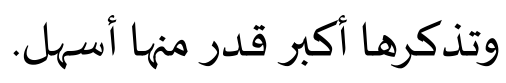

\section{2-2 2 - 2 القراءة المكثفة والموسعة}

2-2-1 القراءة المكثفة: تعد القراءة المكثفة مهمة جدا لدارسي اللغة العربية من الناطقين بغيرها، حيث تعد هي العمود الفقري في برامج تعليم العربية، وهي تتم تحت إشراف

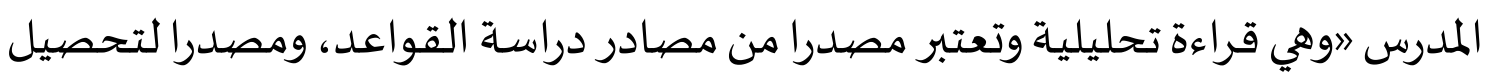

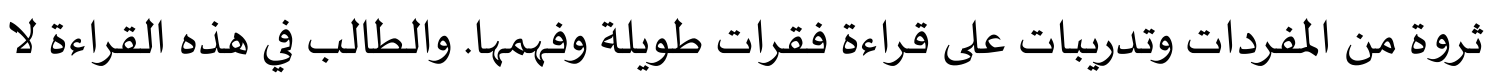

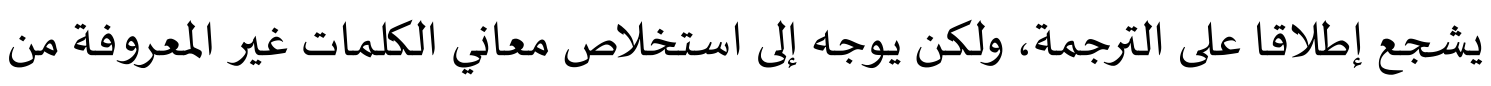

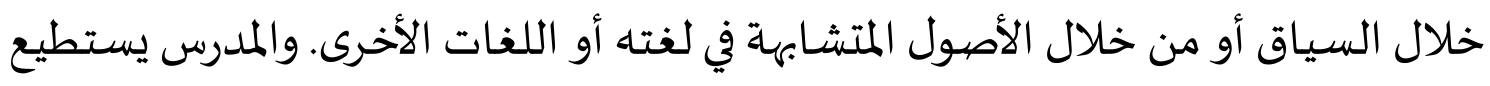

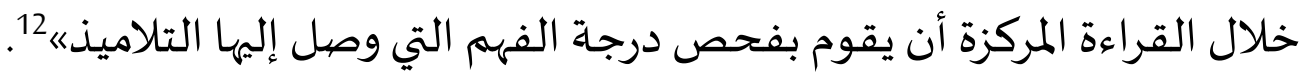

1010 - الناقة، محمود كامل، (1985)، تعليم اللغة العببية للناطقين بلغات أخرى: أسسه، أسسه مداخله، طرق أسقا

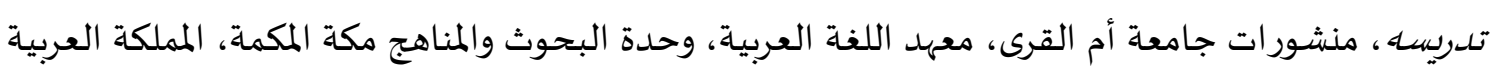
السعودية، ص:139. (139.

$$
11 \text { - إسماعيلي علوي، امحمد. التواصل الإنساني (مرجع سابق)، ص:53. }
$$
12 - الناقة، محمود كامل. تعليم اللغة العببية للناطقين بلغات أخرى (مرجع سابق)، ص: 86. 
نستخلص مما سبق، أن القراءة المكثفة تقوم على أساس التحليل الدقيق، وذلك من

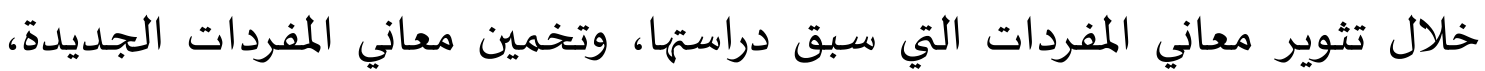
والوقوف عند تفاصيل القواعد. ويمكن تحديد خصائص القراءة المكثفة فيما يلي 13: - القراءة المكثفة هي القراءة التي تجري داخل صفوف الدراسة وبتوجياه من المعلم. - تعمل على تزويد المتعلم بمفردات اللغة وتراكيها.

- تنمية قدرة الطالب على الفهم التفصيلي حيث تصبح له القدرة على تفكيك النص إلى جزئيات مقصيودة من المفردات والتراكيب ومراعاة رموز الترقيم والحركات الإعرابية. - يجب أن يكون النص متحديا للطالب لا صيادما لله. - هدفها تنمية المهارات القرائية والمفردات لدى المتعلم الناطق بغير العربية، كما أن القراءة المكثفة تعتمد على الكتاب المتعدد الموضيوعات. 2.2.2 القراءة الموسعة: يقصد بالقراءة الموسعة، "ذلك النوع من القراءة الذي يستهدف

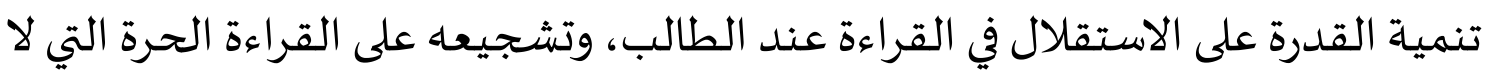

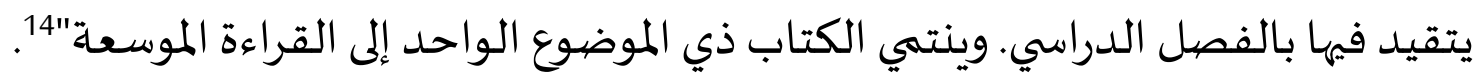
نستخلص، من التعريف السابق، أن القراءة الموسعة هي قراءة حرة تكون خارج حدود

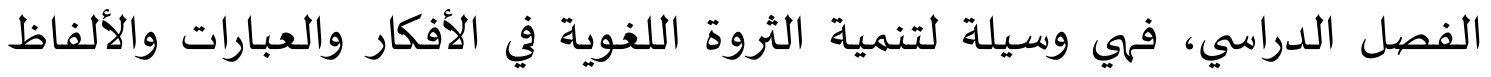

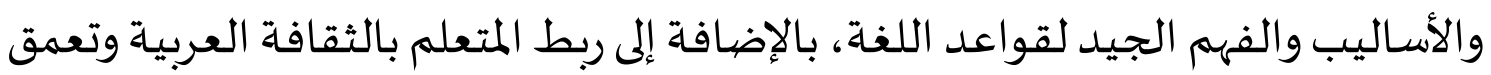
أفكاره، مما يسهم في تنمية مهارة الكتابة والتعبير الشفوي عند الطالب، لهذا يؤكد الباحثون على أهميتها لمتعلمي اللغات الأجنبية.

13 - الناقة، محمود كامل. تعليم اللغة العربية للناطقين بلغات أخرى (مرجع سابق)، ص: 86.

14 - طعيمة، رشدي أحمد، (1989)، علم اللغة العببية لغير الناطقين بها: مناهجه وأسسه، منشورات المنظمة

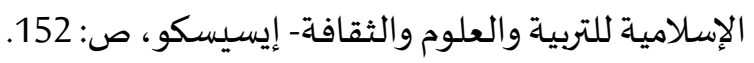


وما نؤكد عليه أن النصوص المختارة في هذا النوع من القراءة يجب أن تكون نصوصيا أصلية كالروايات، والصحف والمجلات وغيرها، وأن تراعي مستوى الطالب وميولاته

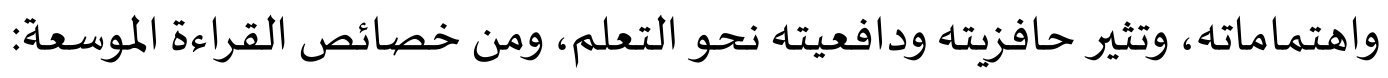
- أن الطالب يمارس القراءة في كل وقت وحين وفي أي مكان. - حرية اختيار الطالب للمواضيع التي تهماه وتشبع ميولاته ورغباته. - القراءة من أجل المتعة والتسلية والاستطلاع. - توسيع معرفة الطلاب بالثقافة العربية من خلال ما قرؤوه. - تسهم في تحسين وتطوير السرعاة والطلاقة في القراءة.

نخلص إلى أهمية كل من القراءة المكثفة والموسعة في تنمية الثروة اللفظية عند متعلم

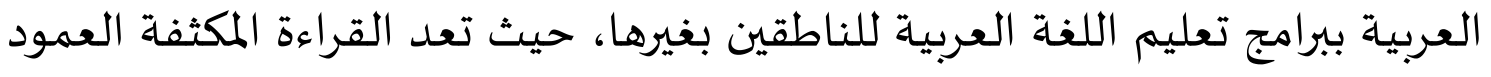

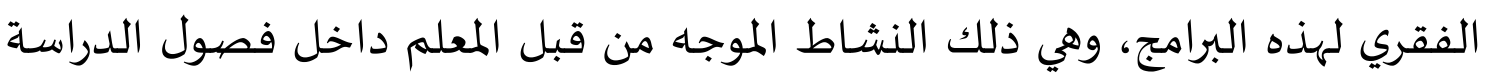

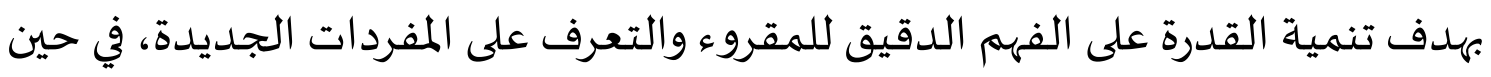

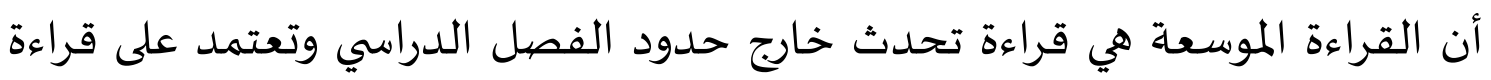

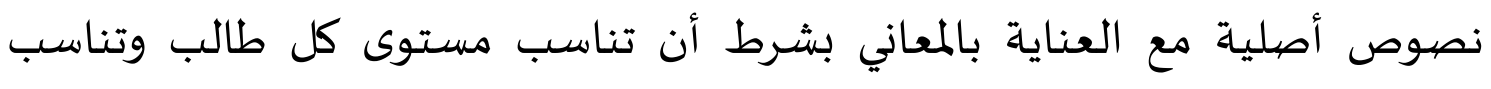

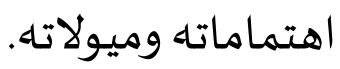

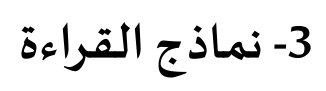

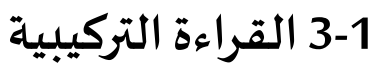

وتسهى أيضا الطريقة الجزئية لأهها تنطلق من الجزء إلى الكل، ومن الخاص إلى العام،

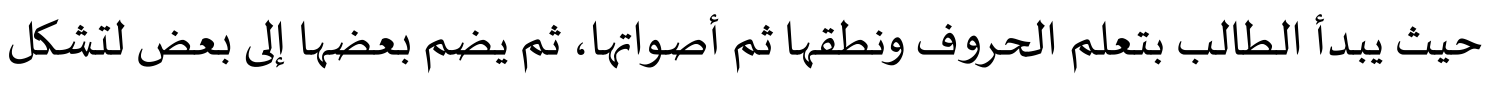

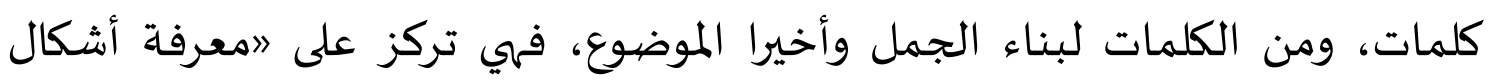

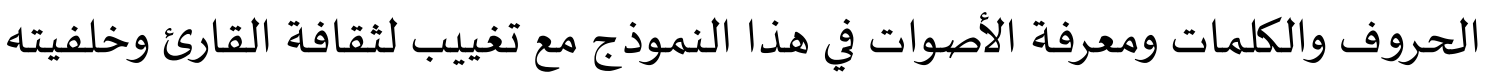
المعرفية وأي عوامل أخرى تساعده في فهم النص، فهو يفهم النص من داخله لا من فن فئن 
خارجه؛15. وتشبـه هذه الطريقة بصورة العالم الذي يفحص كل التفاصيل الدقيقة لبعض الظواهر عن طريق استعمال العدسة المكبرة أو المجهر 16.

$$
\text { وهذا النموذج يتخذ طريقتين 17 اثنتين: }
$$

3-1-1 طريقة الحروف: وهي من أقدم طرق تعليم القراءة، حيث يبدأ المعلم بتعليم الطلاب بنطق الحروف(ألف، باء، تاء...)، وهي تتخذ عدة أشكال:

- الترتيب الألفبائي: يعلم المعلم الطلاب الحروف حسب ترتيها الألفبائي (أ، ب، ت، ث، ج، ح.)، وبعد ذلك ينتقل بهم إلى تعلم الرموز بأشكالها مع الحركات ثم الكلمات فالجمل. - الترتيب الأبجدي: تعتمد هذه الطريقة تعليم الطالب الحروف حسب ترتيبها الأبجدي وليس الألفبائي (أ، ب، ج، د/ هـ، و، ز/ح، ط، ي / ك،ل، م، ن...) ثم الرموز بأشكالها مع الحركات، ثم الكلمات فالجمل فالفقرات.

- تعليم الأسـماء والرموز والحركات: يعلم المعلم الطلاب الحروف من الأول إلى الأخير مع الحركات، وتبدأ بالفتحةة، ثم الكسرة، ثم الضمة وأخيرا السكون.

3-1-2 طريقة الأصيوات: يتم البدء في هذه الطريقة بالحرف مع صوته ولا تعنى باسماه إلا أخيرا، وهي تتخذ شكلين:

$$
\begin{aligned}
& \text { - البدء بالحرف مع صوته مع الحركات كلها (أَ، أُ، إِ، أْ، بَ، بُّ، بِ، بْر...) } \\
& \text { - البدء بالحروف جميعها مع حركة واحدة: (أَ، بَ، تَ، شَ، جَ...) }
\end{aligned}
$$

3-2 القراءة التحليلية

15 - صنوبر، أحمد عبد الجبار. تلدريس مهارة القراءة: النظرية والتطبيق (مرجع سابق) ص: 247. 16 - Brown, H.Douglas (2000). Teaching by principles: An interactive approach to language pedagogy, second edition, Pearson education, p: 299.

17 - طعيماة، رشدي أحمد، (1986)، الممجع في تعليم اللغة للناطقين بلغات أخرى، مطابع جامعة أم القرى، معهد

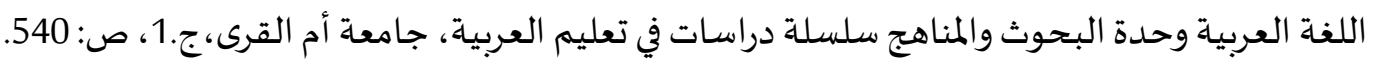


وتسهى أيضا الطريقة الكلية، لأنها تنطلق من الكل إلى الجزء حيث ليبدأ القارئ

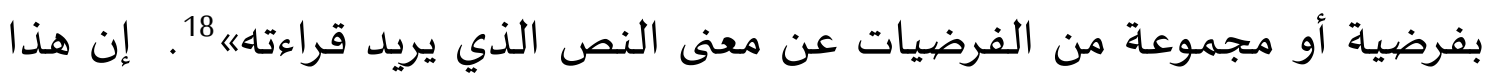

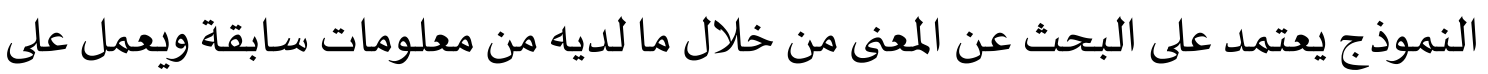

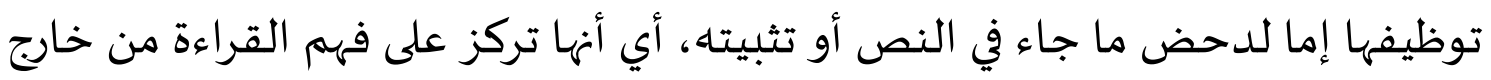
النص. تتخذ القراءة التحليلية ثلاث طرق 19

3-2-1 طريقة الكلمة: تعرض هذه الطريقة على الطالب مجموعة من الكلمات مع صهورها

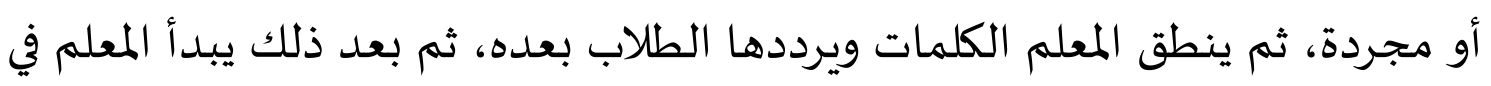
تجريد الحروف ويدرباه على تكوين جمل بها.

3-2-2 طريقة الجملة: يعرض المعلم على الطالب جملا قصيرة ذات معنى يرددها الطلاب

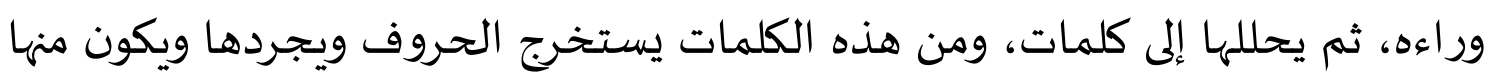
كلمات جديدة وهكذا.

3-2-3 طريقة المد: تبدأ هذه الطريقة بالحروف الممدودة، أي تبدأ بكلمات بسيطة فيها

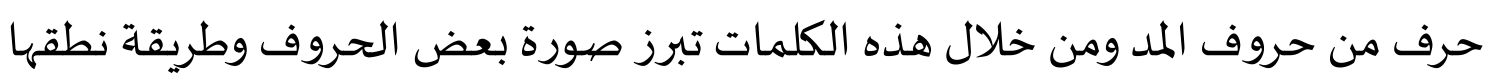

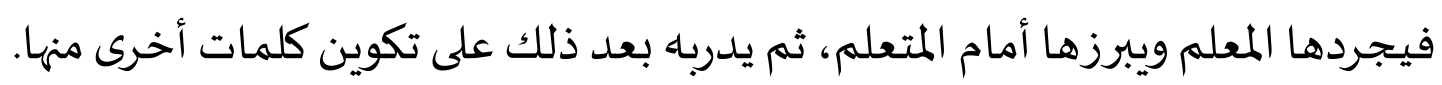
نخلص، إذن، إلى أن القراءة التركيبية تسعى إلى تمكين الطلاب من جمع أكبر عدد من

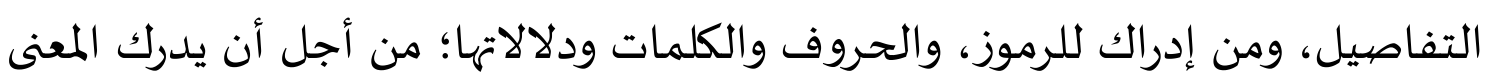

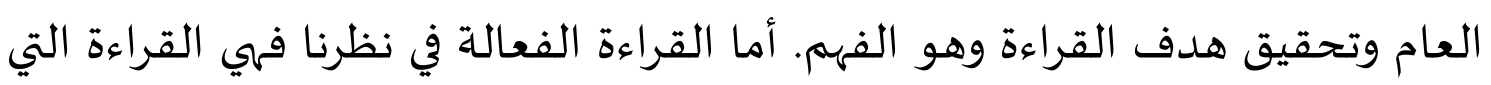

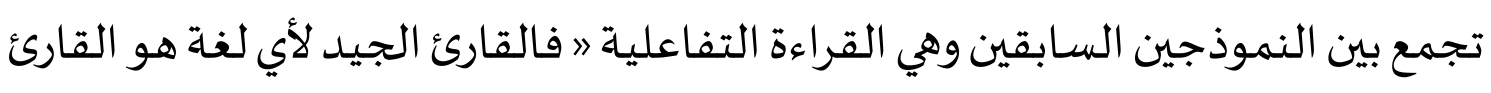

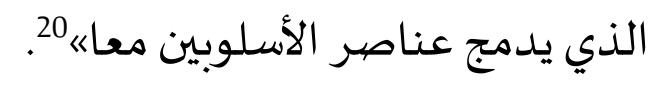

4 - بعض استر اتيجيات تدريس القراءة

4-1 استر اتيجية القراءة السريعة الشـاملة

18 - صنوبر، أحمد عبد الجبار، تلدريس مهارة القراءة النظرية والتطبيق (مرجع سابق)، ص: 247.

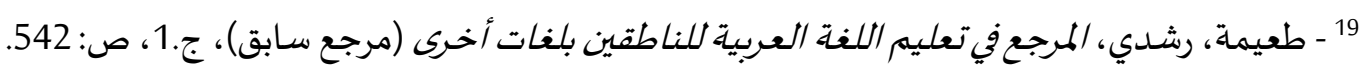

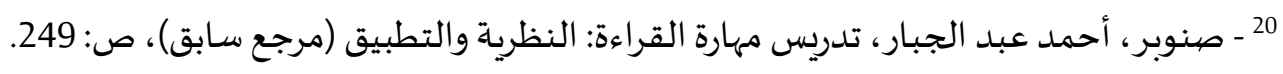


تعد استراتيجياة القراءة السريعة الشاملة من أكثر الاستراتيجيات قيمة للمتعلمين، وهي اتقوم على المرور السريع بالعين على نص كامل؛ وذلك من أجل استخلاص المعنى العام للنص. وهذه الاستراتيـجية مفيدة للطالب حيث تمكنها من الفهه العام وديتطيع التنبؤ بالغرض العام من الفقرةه"21، ومن السمات المميزة للقراءة السريعة هي فهم الكلمات بدون التركيز على الحرف. القراءة تكون صامتة وعدم قضياء وقت أكبر مع العبارات أي أهها مهارة التصفح السريع مع الابتعاد عن معاني الكلمات والأحرف من أجل استخلاص المعنى العام للمقروء. ويرى براون Brown أنه يمكن للمعلم أن يدرب طابها على تصفح بعض المقاطع والفقرات، وذلك بهدف استخلاص معانيها من خلال منحهم 30 ثانية مثلا لينظروا خلالها إلى بعض الصفحات من النص؛ بعدها يتم إغلاق الكتب ويخبرون المعلم بما فهموه.22.

4-2 استر اتيجية القراءة المسحية

تعد استراتيجية القراءة المسحية من أهم استراتيجيات تعلم القراءة، وتكمن أهمية هذا المستح في كون الأستاذ يطلب من طاباه البحث عن معلومة محددة دون قراءة النص كاملا حيث تفيده هذه المعلومة في التعرف على النص وفهم معانيـه وتساعده في فهماه بعد ذلك دون أن يقرأ النص كاملا23.

4-3 استر اتيجية التخمين

تعد استراتيجية التخمين من أهم الاستراتيجيات في تدريس اللغة العربية للناطقين بغيرها عموما، وفي تدريس القراءة والمفردات بشكل خاص، كما أنها مهمة حتى بالنسبـة للمتكلم الأصلي باللغـة فالطالب غير ملزم بمعرفة كل المفردات والتراكيب فهو ״لا يحتاج الرجوع إلى القاموس كلما وجد مفردة لا يعرفها، أو كتب النحو عندما يجد تركيبا غريبا إناه يخمن المعنى وبذلك تستمر عملية القراءة وتستمر الفائدة منها《24.

21 - -Brown, H.Douglas. Teaching by principles: An interactive approach to language pedagogy, p: 308. 22 - Brown, H.Douglas. Teaching by principles: An interactive approach to language pedagogy, p: 308. 23 - صنوبر، أحمد عبد الجبار. تدريس مهارة القراءة: النظرية والتطبيق (مرجع سابق)، ص: ص:259. 24 
لا تتم عملية التخمين إلا بتوفر ثلاثة شروط أساسية وهي القارئ، والنص المقروء

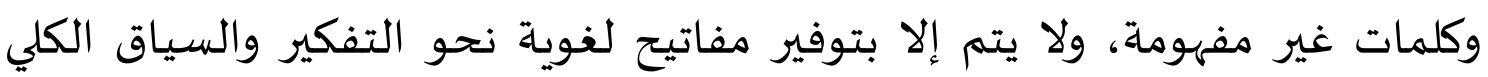

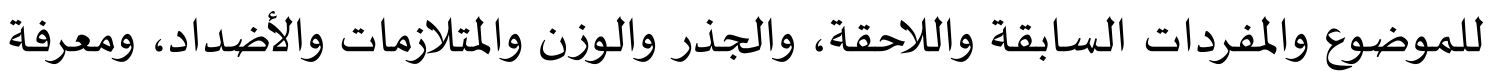

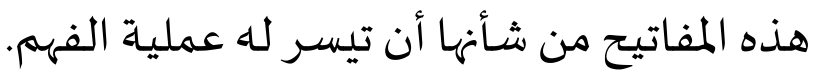

وفي نظرنا فإن هذه الاستراتيجية من الاستراتيجيات الفعالة في مجال تعليم اللغة

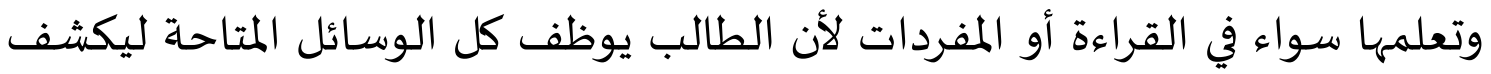

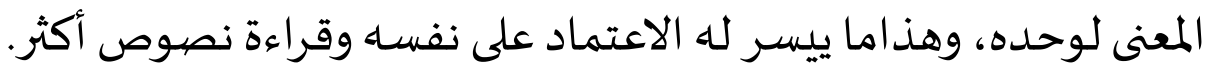

\section{SQ3R 4-4 استر اتيجية}

وضعت استراتيجية SQ3R من طرف فرانسيس روبنسون Francis Robinson في كتابه الدراسة التفاعلية Effective Study من أجل مساعدة الطلاب على قراءة النصيوص بطريقة فعالة، وهي تتكون من خمس خطوات كما يشير إلى ذلك اسمها. يقوم الطالب في هذه الاستراتيجية بخمس خطوات 25 أساسية وهي:

- تصفيح، والمقصود بها القراءة المسحية للمادة المراد قراءتها من أجل الحصول على معلومات عامة، وهذه الخطوة لا تستغرق وقتا طويلا وإنما تهيئه نفسيا للقراءة. الطالب تساؤلات حول النص وماذا يمكن أن يستخلص منها. وهذه هي التساؤلات التي تساعد على تذكر المعلومات فيما بعد.

- Read: اقرأ، بعد التصفح وطرح الأسئلة تبدأ عملية القراءة بهدف الإجابة عن جميع

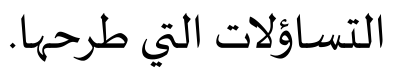

- Recite Revie-

25 - صنوبر، أحمد عبد الجبار.تدويس مهارة القراءة النظرية والتطبيق (مرجع سابق)، ص:261. 


\section{QS4R 4-5 استر اتيجية}

قام إيلين توماس وألان روبنسون Robinson Alan \&Ellen Thomas بتطوير QS3R إلى Improvingbook for teachers والذي نشر في بوسطن سنة

$$
\text { وتمر هذه الاستراتيجية بست مراحل } 27 \text { وهي: }
$$

النص وربط الصور المرافقة بالنص وقراءة الفقرة الأولى والفقرة الأخيرة.

يستخلص مناء.

$$
\text { -Reading - وفيها يتم البحث عن إجابات للأسئلة المطروحة. }
$$

- Reflect محاولا البحث عن الفكرة أو الأفكار الأسساسية. - Recite - Review - R - التقييم حيث يقيم الطالب ما قرأ.

SQ10R 4-6 استر اتيجية

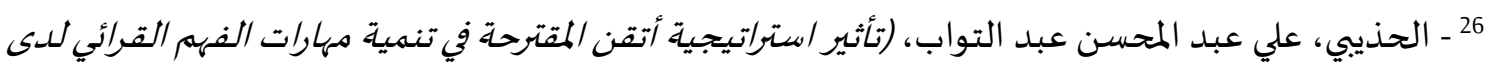

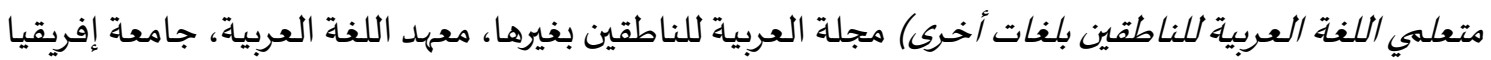

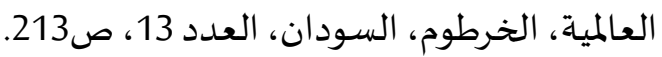

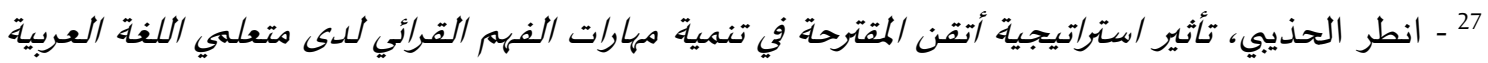

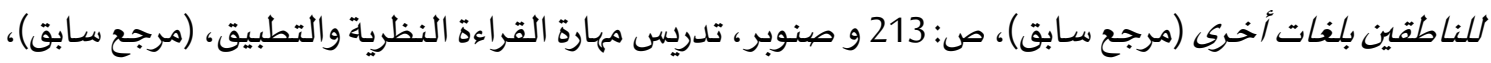


قام مايكل شونيسي Michael Shaughnessy بتطوير استراتيجية SQ3R سنة 1994، إلى

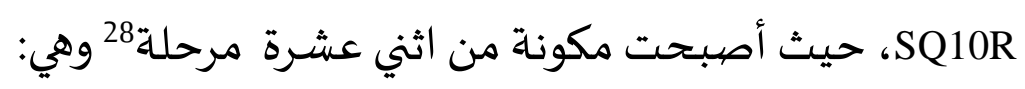

مرحلة التساؤل Question، ومرحلة القراءة Read، مرحلة المراجعة Review، ثم مرحلة

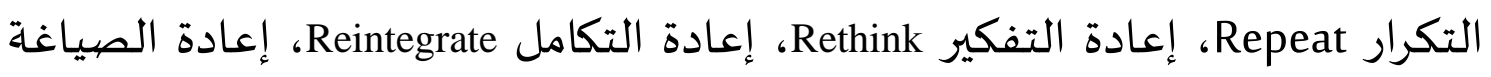

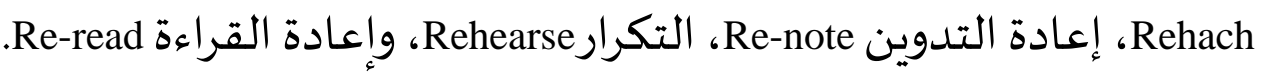
نرى بأن استراتيجية SQ3R هي الأمثل والأكثر فعالية في مجال تعليم العربية للناطقين بغيرها ونظرا لكونها تمر بمراحل دقيقة فالطالب تكون عنده القدرة على الإجابة عن

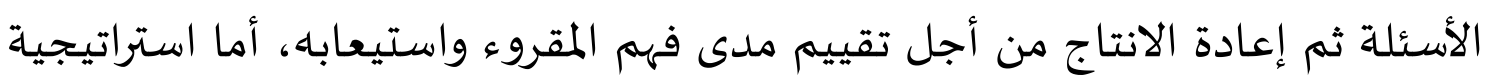

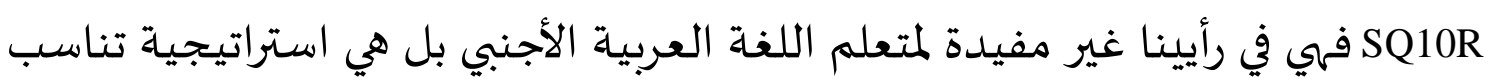
أكثر طلاب الجامعات ممن لهم مستوى عالي ومتميز.

إن استراتيجية تعليم القراءة استراتيجية مهمة ولا بد أن يتم التنويع في التقنيات

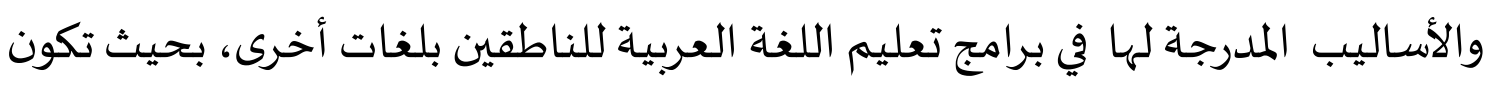

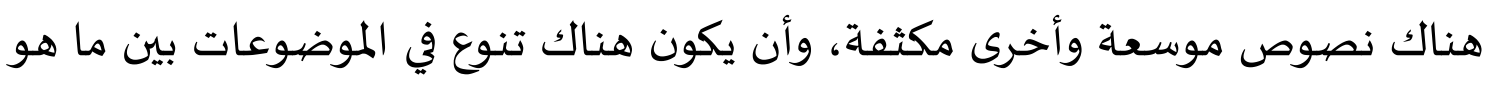

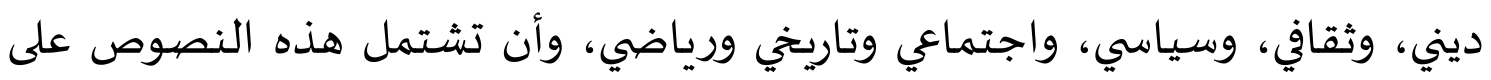

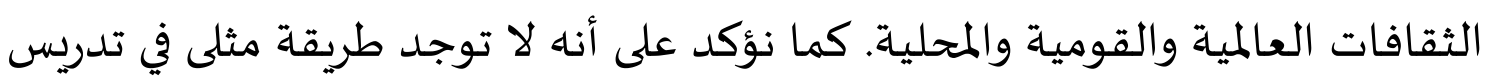

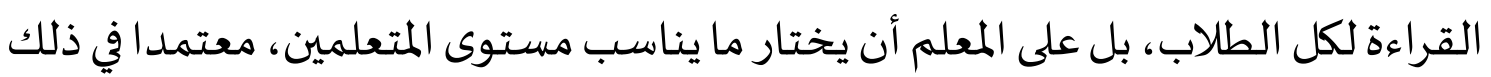
على حساه التربوي وخبرته في المجال.

\section{خاتمة}

تحدث البحث عن مهارة القراءة وماهيتها وأثرها وأهميتها في مجال تعليم اللغة العربية

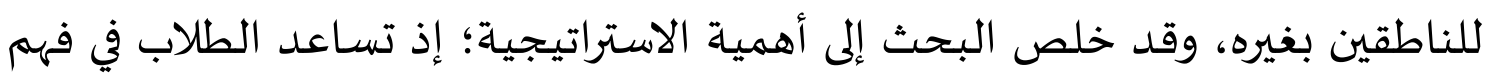

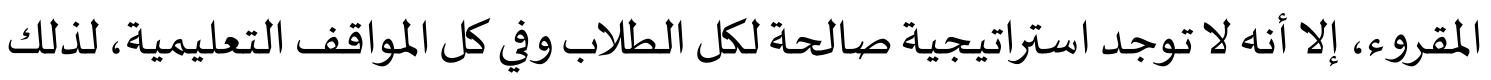

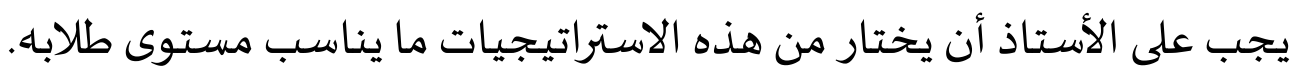

\footnotetext{
28 - تأثير استراتيجية أتقن المقترحة في تنمية مهارات الفهم القرائي لدى متعلهي اللغة العربية للناطقين بلغات أخرى (مرجع سابق)، ص: 213.
} 


\section{ختاما، نقر أنه لا يمكن الإحاطة بكل القضايا والإشكالات المتعلقة بتدريس مهارة

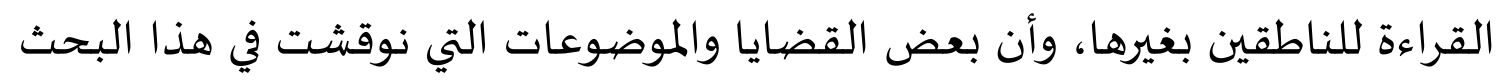

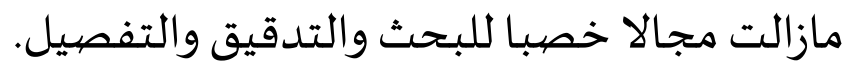

Al-Huzai, Ali Abd Al-Muhsin Abd At-Tawwab, Ta'tsir Istiratijiyah Atqan AlMuqtarahah Fi Tanmiyah Maharat Al-Fahm Al-Qira'I Lada Mut'allimi AlLughah Al-Arbiyah Li An-Nathiqin Bilughatin Ukhra, Majallah Al-Arabiyah Li An-Nathiqin Bighairiha, Ma'had Al-Lughah Al-Arabiyah, Jami'ah Afriqiya Al'Alamiahk Al-Khartoum, Al-Sudan, Al-'Adad 13.

Al-Jaburi, Falah Shalih Husain, Thuruq Tadris Al-Lughah Al-Arabiyah Fi Dha'i Ma'ayir Al-Jaudah Asy-Syamilah Th1, Dar Al-Ridhwan Li Al-Nasyr wa AlTauzi', Amman (2015)

Al-Naqah, Mahmud Kamil, Al-Marja' Al-Mu'ashir Fi Ta'lim Al-Arabiyah Li AlNathiqiin Bighairiha, Th1, Dar Al-Fikri Al-'Arabi, Al-Qahirah, Mishr (2017).

, Ta'lim Al-Lughah Al-Arabiyah Li An-Nathiqiin Bi Lughat Ukhra: Ususuhu, Madakhiluhu, Thuruq Tadrisihi, Mansyrat Jami'ah Um Al- Qura, Ma'had AlLughah Al-Arabiyah Wahdah Al-Buhuts wa Al-Manahij, Makkah AlMukarramah, Al-Mamlakah Al-Arabiyah Al-Su'udiyah (1985).

Brain, Tomlinson. Language Acquisition and devlopment studies of Learners of first and others languages, Athenaeum press Ltd, tyne and wear, Britain (2007).

Brown, H.Douglas . Teaching by principles: An interactive approach to language pedagogy, second edition, Pearson education (2000).

Busyuk, Al-Musthafa, Ta'lim wa Ta'allum Al-Lughah Al-Arabiyah wa Tsaqafatuha, Dirasah Nazhariyah wa Maidaniah Fi Tasykhis Al-Shu'ubat, Iqtirah Muqarabat wa Manahij Didaktikiyah-Bina Tashnif Tsulatsi Al-'Ab'ad Fi Al-Ahdaf AlLisaniyah, Al-Ribath Al-Maghrib.

Isma'ili 'Alawi, Muhammad, At-Tawashul Al-Insani: Dirasah Lisaniyah, Th1, Dar Kunuz Al-Ma'rifah, Amman, Al-Urdun, (2012).

, Taqniyat Tanmiyah wa Tathwir Maharah Al-Qiroah wa Ziyadah AlIsto'ab, Majallah Ulum At-Yarbiyah, Mathba'ah An-Najah Al-Jadidah, AlMaghrib, 'Adad 45, Otober (2010).

Shanubar, Ahmad Abd Al-Jabbar wa Akharun, Tadris Maharah Al-Qiro'ah AnNazhariyah wa Tathbiq, Al-Dalil Al-Tadribi Fi Tadris Maharat Al-Lugha AlArabiyah wa 'Anashiriha Li An-Nathiqiin Bighairi Al-Arabiyah: An-Nazhariyah wa Tathbiq Th1, Mansyurat Markaz Al-Malik Abdullah Al-Dauli Li Khidmah Al- 
Lughah Al-Arabiyah, Dar Wujud Li An-Nasyr wa At-Tauzi', Al-Riyadh, Al-AlMamlakah Al-Arabiyah Al-Su'udiyah (2017).

Thu'aimah, Rusydi Ahmad, Al-Marja', Fi Ta'lim Al-Lughah Li An-Nathiqiin Bilughat Ukhra, Mathabi' Jamiah Um Al-Qura, Ma'had Al-Lughah Al-Arabiyah Wahdah Al-Buhuts wa Al-Manahij Silsilah Dirasat Fi Ta'lim Al-Arabiyah, Jami'ah Umm Al-Qura (1986).

Ta'lim Al-Lughah Al-Arabiyah Li Ghair An-Nathiqiin Biha: Manahijuhu wa Usushu, Mansyurat Al-Manazhamah Al-Islamiyah Li At-Tarbiyah wa Al-Ulum wa At-Tsaqafah -ICESCO, Al-Ribath Al-Maghrib (1989). 